RESEARCH ARTICLE

\title{
Knowledge of Beneficiaries about Pradhan Mantri Fasal Bima Yojanain Tumkur District of Karnataka
}

\author{
Darshan $\mathbf{Y}^{1 *}$, Ramakrishnan $\mathbf{K}^{1}$, Pushpa $\mathrm{J}^{1}$, Prabakaran $\mathbf{K}^{2}$ \\ $1 *$ Department of Agricultural Extension and Rural Sociology, Agricultural college and Research Institute, TNAU, Madurai \\ ${ }^{2}$ Department of Agricultural Economics, Agricultural College and Research Institute, TNAU, Madurai
}

\begin{abstract}
Pradhan Mantri Fasal Bima Yojna (PMFBY) is a crop-based insurance policy designed to help farmers who have suffered crop loss or damage. During the year 2020-21, a research conducted in the Tumkur district of Karnataka the showed the highest number of insurance units (895) compared to other districts of the Karnataka. The findings of the study revealed that the majority of the beneficiaries (52.50\%) had a medium knowledge level about Pradhan Mantri Fasal Bima Yojana. The study's findings underline the importance of profile characteristics namely education, landholding, material possession, extension agency contact, source of information, innovativeness, training attended, economic motivation and mass media exposure that had a positively significant relationship at one per cent level of probability. Whereas variables such as annual income and social participation had a positively significant relationship at five per cent level of probability with beneficiaries' level of knowledge. On the other hand, Crop loan availability and disaster occurrence pattern had no significant relationship with the knowledge level of the beneficiaries about Pradhan Mantri Fasal Bima Yojana.
\end{abstract}

Keywords: knowledge, Pradhan Mantra Fasal Bima Yojana, crop insurance

\section{INTRODUCTION}

Agriculture is the economic backbone of india. Agriculture employed 41.49 per cent of the workforce in 2020 and its contribution to GDP climbed to 19.90 per cent in 2020-21, up from 17.80 per cent in 2019-20 (Directorate of Economics and Statistics). Over two-thirds of India's agricultural land is rain-fed. According to data, as the week ending March 26, 2020 , almost 42.00 per cent of India's land area is experiencing drought, with $6 \%$ of that being severely dry. In India, agriculture referred to as a "Gamble of Monsoon." Because agriculture was more reliant on the weather, even small change in any stage of the crop can have an impact on crop growth and on farmers' livelihoods. Natural calamities such as drought, cyclones, floods, landslides, storms, and earthquakes threaten productivity of crops and farm income on a regular basis. Aside from natural catastrophes, there are man-made disasters such as pesticides, fires, sale of phoney seeds, price crashes, fertilisers, and so on.

All of these factors had a notable impact on farmers' income.Due to changes in government policies, many structural changes have occurred in India's agricultural environment. Farmers are even now at the mercy of the gods, despite the fact that farming has come a long way since then.The riskbearing capability of marginal and small farmers is quite limited. To reduce risk and uncertainty in agriculture, The central government launched the Pradhan Mantri Fasal Bima Yojana on January 13, 2016. For loanee farmers who want to get a crop loan or a KCC account for specified crops, the scheme is required. PMFBY (Pradhan Mantri Fasal Bima Yojana) is a modified crop insurance scheme that out performs its predecessors by providing financial support and national insurance to the farmers in the event of crop failure: to stabilise income, ensure credit flow and encourage farmers to innovate and employ contemporary agricultural practices. A detailed examination of the system and its execution, however reveals that the PMFBY suffer from the same flaws as the preceding plans. Here a brief attempt to evaluate the PMFBY's performance. It makes suggestions for making the PMFBY a longterm mechanism that will preserve farmer incomes and help them overcome their risk aversion.

Recognizing the significance of crop insurance as a tool for risk controlling and uncertainty in agriculture, the current study was executed with the goal of determining the knowledge level of beneficiaries about PMFBY. 


\section{MATERIAL AND METHODS}

The current study was conducted in Tumkur district of Karnataka state as this region had highest insurance units under the scheme of Pradhan Mantri Fasal Bima Yojana even as compared to other regions of the state. Tumkur district comprises of 10 taluks namely i.e. Chikkanayakanahalli, Gubbi, Koratagere, Kunigal, Madhugiri, Pavagada, Sira, Tiptur, Tumkur, Turuvekere. In this Sira and Pavagada taluks were taken purposely on the basis of highest in number of registered farmers under the scheme of Pradhan Mantri Fasal Bima Yojana among all the taluks of the region. Further, six villages from each taluk namely Bukkapattana, Gowdagere, Hulikunte, Kallambella and Sira kasaba from Sira and Balenahalli, Arasikere, Y N Hoskote, Nagalamadike, Nidagal, Thirumani and Chikkahalli from Pavagada taluk were taken purposely on the basis of highest in number of registered farmers under the scheme of Pradhan Mantri Fasal Bima Yojana for the present investigation. The user respondents were chosen using a proportionate random sampling approach and they were referred to as PMFBY beneficiaries because they had more benefited from the scheme. Total 120 respondents were choosen from selected villages for the current investigation. Thus, the total sample size from the selected twelve villages was 120 . The information was gathered using a pre-tested semi-structured interview schedule. Analysing data with the help of several statistical methods like mean, standard deviation, percentage, frequency distribution, mean, percentile and correlation coefficient.

\section{RESULTS AND DISCUSSION}

\section{Overall Knowledge Level of beneficiaries towards PMFBY}

Knowledge was defined in this study as the quantity of information received and kept by the beneficiaries on the scheme of Pradhan Mantri Fasal Bima Yojana. One of the most significant components of adoption behavior is knowledge, which is defined as a body of comprehended information held by an individual. Many scientists believe it is a prerequisite for adoption. Farmers must and should be informed about the most modern schemes and technology to encourage adoption. On this basis, it is critical to assess their understanding of the Pradhan Mantri Fasal Bima Yojana, which is highly recommended. With the use of a knowledge study, an attempt to measure the beneficiary's knowledge level about PMFBY. Percentile values were calculated on the basis of beneficiaries' minimum and maximum knowledge scores. The beneficiaries were divided into three categories based on percentile value.
Table 1 : Overall knowledge on PMFBY by beneficiaries

$n=120$

\begin{tabular}{clcc}
\hline SI.no & \multicolumn{1}{c}{ Category } & Frequency & Percentage \\
\hline 1. & Low $(<16)$ & 12 & 10.00 \\
2. & Medium $(16-19)$ & 63 & 52.50 \\
3. & High $(>19)$ & 45 & 37.50 \\
\hline \multicolumn{2}{l}{ Mean $=\mathbf{1 7 . 7 9}$} & & SD $=\mathbf{1 . 9 7}$ \\
\hline
\end{tabular}

The data shown in table 1 concluded that majority of 52.50 per cent beneficiaries had a medium level of knowledge, while 37.50 per cent and 12.00 per cent were high and low level of knowledge, respectively. A comparison of data for these three levels of beneficiaries of knowledge is clearly reveals that beneficiaries had a high knowledge level, implying that the farmers' knowledge level had increased after receiving PMFBY benefits. The findings was supported by the findings of Jambuvant (2017) and Akash tanwar (2019) were found that the majority of beneficiaries had medium knowledge about PMFBY.

The results presented in table 2 revealed that majority of the beneficiaries had higher knowledge with respect to the individual statements 'The types of the risks that are covered under this scheme PMFBY are' (98.33 per cent) followed by 'Prime objective of PMFBY is to provide financial support to crop loss' (95.83 per cent), 'Risk covered are natural fire / lighting / storm / cyclone /flood / drought'. (94.17 per cent), 'The basis for execution of Pradhan Mantri Fasal Bima Yojana is an' (92.50 per cent) and PMFBY is not provides the loan for' (87.50 per cent), 'The crops covered under PMFBY during kharif season are'(86.67 per cent), 'The amount of premium rate for kharif crops under the PMFBY is' (85.00 per cent) and 'PMFBY farmers is optional for farmers, who have taken institutional loans from banks' (84.17 per cent).

The above results could be due to agriculture's gamble with nature, which has resulted in erratic rainfall, scarcity of rainfall, and other factors. There have been heavy rains in some places and no rain in other places. These factors contribute to lower production, food scarcity, and farmer suicide attempts. In light of these considerations, the Indian government introduced the PMFBY, a scheme for crop insurance that differs from previous schemes in that it expands farmer coverage, including crop coverage, increases the sum insured, and lowers the rate of premium for the benefit of farmers. The government has also made it mandatory for all concerned developmental departments, banks, and insurance agencies to publicity the crop insurance scheme's benefits to the farming community. 


\begin{tabular}{|c|c|c|c|}
\hline SI.no & Knowledge Statements & Frequency & Percent \\
\hline 1. & PMFBY is not provides the loan for & 105 & 87.50 \\
\hline 2. & The basis for execution of PMFBY is an & 111 & 92.50 \\
\hline 3. & The crop loss assessment in PMFBY is done by using & 78 & 65.00 \\
\hline 4. & $\begin{array}{l}\text { The remote sensing lab for crop insurance to gave early warnings to the farmers and government } \\
\text { about the losses under PMFBY was established by company }\end{array}$ & 57 & 47.50 \\
\hline 5. & $\begin{array}{l}\text { The Farmers under PMFBY has to intimate individual loss (natural calamities /mid season } \\
\text { losses) within ......... hours to the officials of the department of Agriculture DOA }\end{array}$ & 94 & 78.33 \\
\hline 6. & $\begin{array}{l}\text { The farmers under PMFBY has to intimate post- harvest losses within ..........days to department } \\
\text { of Agriculture DOA }\end{array}$ & 91 & 75.83 \\
\hline 7. & $\begin{array}{l}\text { PMFBY beneficiaries is mandatory for .............farmers, who have taken institutional loans } \\
\text { from banks. }\end{array}$ & 98 & 81.67 \\
\hline 8. & PMFBY farmers is optional for ...........farmers, who have taken institutional loans from banks. & 101 & 84.17 \\
\hline 9. & The reasons for failure of PMFBY is & 87 & 72.50 \\
\hline 10. & The source of funds for government to pay premium in PMFBY is & 50 & 41.67 \\
\hline 11. & The share of premium rate by central and state governments in PMFBY is & 45 & 37.50 \\
\hline 12. & The companies provide Insurance under this scheme (PMFBY) in Tumkur & 70 & 58.33 \\
\hline 13. & Year Of Introduction of PMFBY is & 100 & 83.33 \\
\hline 14. & The crops covered under PMFBY during kharif season are & 104 & 86.67 \\
\hline 15. & The amount of premium rate for kharif crops under the PMFBY is & 102 & 85.00 \\
\hline 16. & Crops covered under PMFBY during Rabi season are & 65 & 54.17 \\
\hline 17. & The amount of premium rate for Rabi crops under the PMFBY is & 72 & 60.00 \\
\hline 18. & The types of the risks that are covered under this scheme PMFBY are & 118 & 98.33 \\
\hline 19. & The companies provide Insurance under this scheme (PMFBY) are & 80 & 66.67 \\
\hline 20. & Prime objective of PMFBY is to provide financial support to crop loss & 115 & 95.83 \\
\hline 21. & The crops covered under PMFBY are Kharif, Rabi, Annual Horticulture crop & 55 & 45.83 \\
\hline 22. & Risk covered are natural fire / lighting / storm / cyclone / flood / drought & 113 & 94.17 \\
\hline 23. & All states \& Union Territories were not covered in PMFBY & 96 & 80.00 \\
\hline 24. & PMFBY is replacement scheme of NAIS / MNAIS & 85 & 70.83 \\
\hline 25. & $\begin{array}{l}\text { In PMFBY the losses arising out of war and nuclear risks, malicious damage and other } \\
\text { preventable risks shall be Included. }\end{array}$ & 43 & 35.83 \\
\hline
\end{tabular}

Other reasons could include farmers discussing claim status with their relatives and neighbors as well as checking their passbook status on a regular basis to learn about the claim settlement. PMFBY is only available for state-notified crops. Crop insurance is available in all three types of banks and crop insurance closing dates are known from their own experience and interactions with bank officials over the years. The majority of beneficiaries had knowledge on how they could file a crop insurance claim in the event of drought, flood, or other localized disasters. Beneficiaries knew that the crop insurance is used in the event of unforeseen circumstances or natural disasters and the scheme is designed to address this. On the other hand, beneficiaries had previously received the claim in the aforementioned situations.

The insurance had already conducted crop cutting experiments on both major and minor crops in most of the farmers' and neighbors' fields. Nearly one-third of beneficiaries were unaware of the state and federal government's share of subsidy premiums under the PMFBY scheme, as some beneficiaries believed the scheme was only available from the central government. Only half of the beneficiaries knew the prescribed premium rates for both rabi and Kharif crops. Some beneficiaries knew the acre/ hectare rate of premium for each crop, but not the exact percentage premium rate for food, oil seed crops, commercial and annual horticultural crops. In practice, only insurance officers conducted crop cutting experiments in the field, while bank and line department officials did not participate, resulting in beneficiaries having a limited understanding of the officials involved in crop cutting experiments.

According to previous studies, the majority of farmers were aware that insurance was only available 
for state-approved crops and that insurance could be obtained from any bank, including Commercial banks, Regional Rural Banks, Primary Agricultural Credit Societies and so on. Crop insurance claims can be made in cases of drought, flood, and other localized calamities. The beneficiaries also knew about closing dates for registering both kharif and rabi crops. The researchers Surve, et al. (2005), Mohapatra et al. (2016), Jambuvant (2017) and Kumar, et al. (2017) have all come to similar conclusions.

\section{Relationship between independent variables with knowledge level of PMFBY beneficiaries.}

\begin{tabular}{|c|c|c|c|c|c|}
\hline SI.no & Independent variables & $\begin{array}{l}\text { Correlation } \\
\text { coefficient (r) }\end{array}$ & $\begin{array}{c}\text { Regression } \\
\text { coefficient }\end{array}$ & t table & P-value \\
\hline 1. & Age & $-.259 * *$ & -.061 & -2.566 & .468 \\
\hline 2. & Education & $.482 * *$ & $.321 * *$ & 2.485 & .012 \\
\hline 3. & Size of Land holding & $.280 * *$ & -.002 & -.118 & .906 \\
\hline 4. & Farming experience & $-.279 * *$ & $.056 *$ & 2.100 & .038 \\
\hline 5. & Annual income & $.234 *$ & $5.230 \mathrm{E}-6$ & .978 & .330 \\
\hline 6. & Material possession & $.241 * *$ & -.068 & -1.113 & .268 \\
\hline 7. & Social participation & $.223 *$ & .189 & 1.100 & .274 \\
\hline 8. & Extension agency contact & $.401 * *$ & $.173 * *$ & 3.489 & .001 \\
\hline 9. & Crop loan availed & .110 & .145 & .723 & .471 \\
\hline 10. & Source of information & $.399 * *$ & $.152 * *$ & 6.727 & .000 \\
\hline 11. & Innovativeness & $.235 * *$ & .055 & .824 & .412 \\
\hline 12. & Training attended & $.346 * *$ & .225 & 1.840 & .069 \\
\hline 13. & Mass media exposure & $.594 * *$ & $.123 * *$ & 2.791 & .006 \\
\hline 14. & Disaster occurrence pattern & .123 & -.013 & -.090 & .929 \\
\hline 15. & Economic motivation & $.408 * *$ & $.226 * *$ & 2.929 & .004 \\
\hline
\end{tabular}

The results shown in table 3 revealed that the independent variables of education, size of land holding, material possession, extension agency contact, source of information, innovativeness, training attended, economic motivation and mass media exposure had a positively significant relationship at one per cent level of probability. One of the possible reasons is that farmers with more education will have a higher level of knowledge. Farmers with high land holdings typically earn more money and have a better socio-economic status. Beneficiaries had a habit of looking into every possible source of information to get more knowledge and earn more money. The farmers who contacted the extension personnel of developmental departments frequently might have bared to various kinds of information and gained more knowledge on Crop Insurance Scheme. Mass media exposure intensifies the ability of the beneficiaries to get more information about PMFBY scheme and in turn widens the mental horizon of the beneficiaries to accept and adopt the PMFBY scheme. Economically motivativated beneficiaries' desire to obtain money, has varied according to the status of economic life within different social environments due to this knowledge had significant to economic motivation. Social participation and annual income had a positively significant relationship at five per cent level of probability. The possible reason for this is involvement in activities that allow a person to interact with others in society or community and express interpersonal interactions outside of the home that leads to gain more knowledge. The variables of age and farming experience were negative and significant with the knowledge because PMFBY is a recent year (2016) scheme for the protection of farmers during natural calamities, could be well known by the young generation rather than old age group PMFBY beneficiaries and Majority of the beneficiaries with 20-39 years of farming experience and it could be witnessed that experienced farmers having high knowledge due to continuous medium extension contact as well as medium mass media utilization, whereas some other factors like crop loan availed and disaster occurrence pattern had shown non-significant relationship with the knowledge level of beneficiaries because more number of the PMFBY beneficiaries belong to medium disaster occurrence pattern category, which resulting eager to the acquisition of knowledge on disasters and insurance to protect beneficiaries interest and beneficiaries had more knowledge due to medium to high extension agency contact and social participation. 


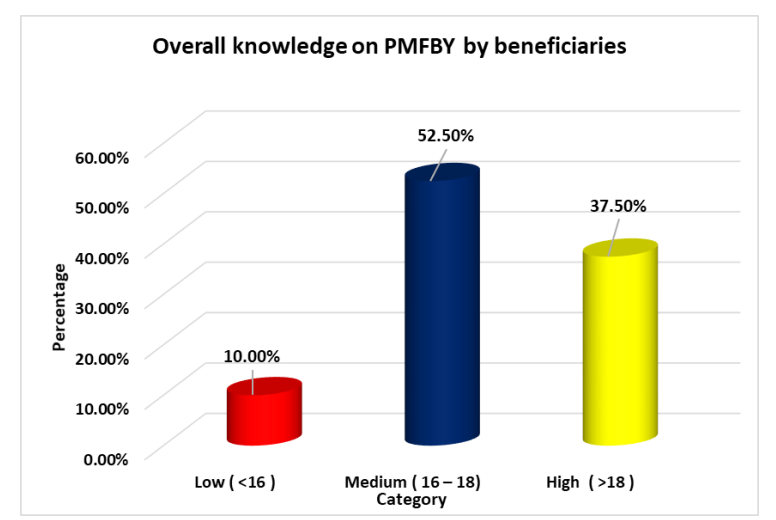

Figure 1: Overall knowledge on PMFBY by the beneficiaries

\section{CONCLUSION}

In the current study beneficiaries' knowledge about PMFBY was found to be medium. The variables likeeducation, land holding, material possession, extension agency contact, source of information, innovativeness, training attended, economic motivation and mass media exposure had a positively significant relationship at one per cent level of probability. Whereas, variables such as social participation and annual income had a positively significant relationship at five per cent level of probability with the knowledge level of beneficiaries. The co-efficient of determination (R2) was 0.680 which revealed that 68.00 per cent of the variation in the knowledge level of beneficiaries was together explained by all the independent variables. The variables such as, crop loan availed and disaster occurrence pattern had non-significant relationship with the knowledge level of beneficiaries.

\section{REFERENCES}

Akash and S. K. Johri. 2019. Knowledge of Wheat Growers about Pradhan Mantri Fasal Bima Yojana. Int. j. curr. microbiol. appl. sci. International Journal of Current Microbiology and Applied Sciences ., 7: 1761-1768.

Jambuvant, D.S. 2017. Knowledge and attitude of farmers towards crop insurance scheme. M.Sc. Thesis, College of Agriculture, Latur Vasantrao Naik Marathwada Krishi Vidyapeeth, Parbhani-431402

Kumar and Arbind Kumar Sai. 2017. Knowledge and adoption extent of farmers about crop insurance scheme in Etawah district (UP). J. pharmacogn. phytochem .,6: 154-156.

Mohapatra and Kaur Manmeet. 2018. Farmers knowledge about the agricultural insurance scheme in Punjab. J. Ext. Educ. ., 1 : 49-53.

Surve and S. D. Sarnaik. 2005. A study on attitude of the farmers towards National Agricultural Insurance Scheme in Parbhani and Hingoli Districts of Maharashtra.J. Soil. Crop., 2 : 356-359. 